\title{
Gaschromatographische Bestimmung von Pregnandiol, Pregnantriol und Pregnantriolon im Urin
}

\author{
Von H.-Сh. Curtrus
}

Technische Assistenz: M. MüLLER

Aus dem Chemischen Laboratorium der Universitäts-Kinderklinile Zürich (Direktor: Prof. Dr. A. Prader)

(Eingegangen am 8. September 1965)

\begin{abstract}
In der vorliegenden Arbeit wird eine Methode zur gaschromatographischen Bestimmung von Pregnandiol, Pregnantriol und Pregnantriolon im Urin beschrieben. Die Methode besteht in der enzymatischen Hydrolyse der Steroidkonjugate mit Glucuronidase, der Extraktion und Reinigung der Extrakte und der Gaschromatogräphie der Steroide als Trimethylsilyläther. Durch Zumischen von Testsubstanzen zu Urin wurde die Ausbeute und die Reproduzierbarkeit der Methode ïberprüft. Die Resultate stimmen mit den Ergebnissen der konventionellen Analysenverfahren anderer Autoren überein. Die Empfindlichkeit pro Probe liegt im Nanogrammbereich.
\end{abstract}

A method is described for the gas chromatographic determination of urinary pregnanediol, pregnanetriol and pregnanetriolone. The method entails the enzymic hydrolysis of the steroid conjugates with glucuronidase, extraction and purification of the extracts and gas chromatography of the steroids as their trimethylsilyl ethers. The yield and reproducibility of the method were tested by the addition of test materials to urine. The results were in complete agreement with those obtained by other authors with conventional analytical techniques. The sensitivity per sample is in the order of nanograms.

Die Progesteron-Metaboliten Pregnandiol, Pregnantriol und Pregnantriolon werden im Urin als Konjugate, und zwar hauptsächlich als Glucuronide ausgeschieden. Ihre quantitative Bestimmung setzt daher eine hydrolytische Spaltung in Steroid- und Glucuronsäure voraus. Dazu stehen im wesentlichen zwei Möglichkeiten zur Verfügung, die hydrolytische Spaltung durch $\beta$-Glucuronidase oder Ketodase (1) oder die Spaltung durch Solvolyse (2). - Beide Methoden wurden für Forschungsund klinische Zwecke intensiv angewendet. Die anschließende Identifizierung und quantitative Bestimmung der einzelnen Steroide gestaltete sich für die Routine im Klinik-Laboratorium mühsam und zeitraubend. Meist lagen den Methoden säulen-, papier- oder dünnschichtchromatographische Verfahren zugrunde (3-7). Sie erlaubten zum Teil nur eine semiquantitative Erfassung. Diese Nachteile wurden trotz der großen klinischen Bedeutung der Steroidanalysen in Kauf genommen.

Nachdem wiederholt (8-11) gezeigt worden ist, daß sich die Steroidhormone ohne Zersetzung gaschromatographieren lassen, und nachdem sich verschiedene Arbeiten mit der qualitativen und quantitativen Gaschromatographie dieser Verbindungen im biologischen Material befaßt hatten (12-15), erschien es uns wünschenswert, eine für den klinischen Routinebetrieb geeignete $\mathrm{Me}$ thode für die quantitative Bestimmung von Pregnandiol, Pregnantriol und Pregnantriolon mittels Gaschromatographie auszuarbeiten.

\author{
Methodik \\ Geräte \\ „F 20“ Fraktometer der Fa. Perkin-Elmer mit Flammenionisations- \\ detektor \\ XE 60 Chromatographiesäule vion $2 \mathrm{~m}$ Länge und 2,7 $\mathrm{mm} \varnothing$ \\ Hamilton Mikrospritzen $10 \mu l$, auf $0,1 \mu l$ graduiert \\ Thermostatisiertes Wasserbad \\ Wärmeschrank \\ Exsikkator mit $\mathrm{P}_{2} \mathrm{O}_{5}$ als Trocknungsmittel.
}

\section{Chemikalien}

Trimethylchlorsilan, z. B. Fluka, Art.-Nr. A 57998

Hexamethyldisilazan, z. B. Fluka, Art.-Nr. 54429

Aceton, z. B. Fluka, Art.-Nr. A 50045

Äthanol, z. B. Fluka, Art.-Nr. A 50231 puriss.

Ather, z. B. Fluka, Art.-Nr. A 52689 puriss.

Hexan, z. B. Merck, Art.-Nr. 9688

Methylenchlorid, z. B. Fluka, Art.-Nr. A 55634

Toluol, z. B. Merck, Art.-Nr. 98325

Natriumcarbonat, z. B. Merck, Art.-Nr. 6392

Pregnandiol, z. B. Calbiochem, Art.-Nr. 529853

Pregnantriol, z. B. Merck, Art.-Nr. 8968

Pregnantriolon, z. B. Merck, Art.-Nr. 8969

Allo-Pregnandiol, z. B. Merck, Art.-Nr. 8955

Androsteron, z. B. Merck, Art.-Nr. 8958

Etiocholanolon, z. B. Calbiochem, Art.-Nr. 341294

Dehydroepiandrosteron, z. B. Calbiochem, Art.-Nr. 254098

Pregnanolon, z. B. Sigma, pfs

$\beta$-Glucuronidase, Sigma, Art.-Nr. 105-8/Type I (aus Bakterien)

Natriumhydroxyd, z. B. Merck, Art.-Nr. 6496

Natriumsulfat, z. B. Merck, Art.-Nr. 6649

Kalium-Dihydrogenphosphat, z. B. Merck, Art.-Nr. 4873.

\section{Reagenzien}

Standardlöstungen: Je $10 \mathrm{mg}$ Pregnandiol, Pregnantriol und Pregnantriolon jeweils in Äthanol ad $100 \mathrm{ml}$.

Testgemisch: Je $10 \mathrm{mg}$ Pregnandiol, Allo-Pregnandiol, Pregnantriol, Pregnantriolon, Androsteron, Etiocholanolon, Dehydroepiandrosteron, Pregnanolon in Äthanol ad $100 \mathrm{ml}$.

Innerer Standard: $10 \mathrm{mg}$ Pregnanolon in Äthanol ad $100 \mathrm{ml}$.

Silylierungsgemisch: Mischung von $3 \mathrm{ml}$ Hexamethyldisilazan $+0,1 \mathrm{ml}$ Trimethylchlorsilan (kühl und verschlossen aufbewahren, jeden 2 . Tag frisch ansetzen.)

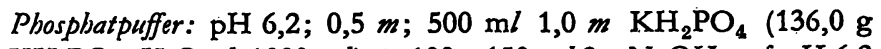
$\mathrm{KH}_{2} \mathrm{PO}_{4}, \mathrm{H}_{2} \mathrm{O}$ ad $\left.1000 \mathrm{ml}\right)+100-150 \mathrm{~m} / 2 n \mathrm{NaOH}$ auf $\mathrm{pH} 6,2$ einstellen, $\mathrm{H}_{2} \mathrm{O}$ ad $1000 \mathrm{ml}$.

Sodalösg. $2 \mathrm{n}: 106,0 \mathrm{~g} \mathrm{Na}_{2} \mathrm{CO}_{3} ; \mathrm{H}_{2} \mathrm{O}$ ad $1000 \mathrm{ml}$.

\section{Vorgehen}

Die inneren Standards werden durch den ganzen Analysengang geführt. 


\section{Hydrolyse}

\section{a) mit Salzsäıre}

Diese Vorschrift hält sich im wesentlichen an die $\mathrm{Me}$ thode von KLOpper (16). $2 \mathrm{ml}$ Pregnanolon-Lösg. werden in einem Rundkolben zur Trockene eingedampft. Nacheinander werden $25 \mathrm{ml}$ Urin und $20 \mathrm{ml}$ Toluol zugegeben und zum Sieden erhitzt. Nach Zusatz von $2,5 \mathrm{ml}$ konz. Salzsäure wird 10 Min. am Rückfluß gekocht. Die Lösung wird dann auf Zimmertemperatur abgekühlt.

\section{Extraktion}

Das Hydrolysat wird $3 \mathrm{mal}$ mit $25 \mathrm{ml}$ Toluol extrahiert, die vereinigten Extrakte $2 \mathrm{mal} \mathrm{mit} 2 n$ Sodalösung ausgeschüttelt und anschließend $5 \mathrm{mal}$ mit je $20 \mathrm{ml}$ aqua dest. neutral gewaschen. Die organische Phase wird nun mit Natriumsulfat getrocknet und eingedampft. Der Rückstand wird in wenig Aceton aufgenommen, in ein kleines Röhrchen überführt und zuerst am Vakuum und nachher im Exsikkator über $\mathrm{P}_{2} \mathrm{O}_{5}$ getrocknet.

\section{b) mit $\beta$-Glucuronidase}

Vorschrift nach R. E. Peterson (17): $\mathrm{Zu} 2 \mathrm{ml}$ in einem Rundkolben getrockneter Pregnanolon-Lösg. werden $25 \mathrm{~m} /$ Urin gegeben und auf $\mathrm{pH}$ 6,2 eingestellt. Nach Zugabe von $5 \mathrm{ml}$ Phosphatpuffer und 2500 Einheiten $\beta$ Glucuronidase wird das Gemisch für $48 \mathrm{Stdn}$. in den Wärmeschrank gestellt. Bakterielle Zersetzung kann durch 3 Tropfen Chloroform vermieden werden.

\section{Extraktion}

Nach 3-maliger Extraktion des Hydrolysats mit $25 \mathrm{ml}$ Äther werden die vereinigten Extrakte zuerst $2 \mathrm{mal} \mathrm{mit}$ etwa $20 \mathrm{ml} 2 n$ Sodalösg. und nachher $5 \mathrm{mal} \mathrm{mit} 20 \mathrm{ml}$ aqua dest. ausgeschüttelt. Die organische Phase muß neutral sein. Dann wird der Äther mit Natriumsulfat getrocknet und am Vakuum eingedampft. Den Rückstand überführt man mit wenig Aceton in ein kleines Reagenzglas, dampft wiederum ab und trocknet im Exsikkator über $\mathrm{P}_{2} \mathrm{O}_{5}$.

\section{Silylierung}

Die getrockneten Proben werden in $0,5 \mathrm{ml}$ Silylierungsgemisch gelöst und in einem mit Schliffstopfen verschlossenen Röhrchen $1 \mathrm{Std}$. in einen Wärmeschrank von $60^{\circ}$ gestellt. Das überschüssige Silylierungsgemisch wird anschließend bei etwa $40^{\circ}$ mit absolut getrocknetem Stickstoff abgedampft (reinster Stickstoff wird durch mehrere Waschflaschen mit konz. $\mathrm{H}_{2} \mathrm{SO}_{4}$ geleitet). Den Rückstand nimmt man in $0,1 \mathrm{ml}$ absolutem Hexan auf. Diese Lösung wird anschließend gaschromatographiert. Wegen der großen Empfindlichkeit gegen Luftfeuchtigkeit ist die Lösung nicht lange haltbar.

\section{Trennsäulenbedingungen}

Säule: XE 60, $2 \mathrm{~m}, 3 \%$ auf Gaschrom P; $\varnothing: 2,7 \mathrm{~mm}$, Kolonnentemperatur: $225^{\circ}, x=16$

Einspritzblocktemperatur: $275^{\circ}$ (Abb. 1) bzw. $285^{\circ}$ (Abb. 3-5).

Stickstoff: $40 \mathrm{ml} / \mathrm{Min}$.

\section{Berechnung}

Bei substanzeigenem innerem Standard errechnet sich die Konzentration der gesuchten Substanz nach der folgenden Formel:

$$
\text { Stoff i (in Gew.- } \%)=\frac{100 \cdot F_{\mathbf{i}} \cdot z_{\mathbf{i}}}{\left(\frac{F_{\mathbf{X}}^{I}}{F_{\mathbf{X}}^{I I}} \cdot F_{z i}-F_{i}\right)\left(100-z_{i}\right)}
$$

$F_{z i}=$ Fläche des Berges i nach Zusatz von $z \%$ des Stoffes i zum Gemisch bei der Analyse II

$\mathrm{F}_{\mathbf{i}}=$ Fläche des Berges $\mathrm{i}$ ohne Zusatz bei der Analyse I

$z_{i}=$ Gew.- $\%$ Zusatz des Stoffes $i$ als Gew.- $\%$. Gehalt des neuentstandenen Gemisches, das gleich 100 gesetzt wird

$F_{x}^{I}=$ Bergfläche eines beliebigen unbeeinflußbaren Berges $\mathrm{x}$ bei der. Analyse I

$\mathrm{F}_{\mathbf{x}}^{\mathrm{II}}=$ Bergfläche des gleichen Berges $\mathrm{x}$ bei der Analyse II.

Wenn kein Pregnanolon in der Analyse zu erwarten ist, kann das Ergebnis nach folgender abgekürzten Formel errechnet werden:

$$
\mathrm{mg} \% \mathrm{x}=\frac{\mathrm{mg} \% \mathrm{St} \cdot \mathrm{F}_{\mathbf{x}}}{\mathrm{F}_{\mathrm{St}}} \cdot \mathrm{F}
$$

$\mathrm{mg} \% \mathrm{St}=$ Konzentration des inneren Standards (Pregnanolon)

Fx = Peakfläche der gesuchten Substanz

$\mathrm{F}_{\mathrm{St}} \quad=$ Peakfläche des inneren Standards (Pregnanolon)

$\mathrm{F} \quad=$ Umrechnungsfaktor (= Fläche Pregnanolon/Fläche gesuchte Substanz bei gleichen Konzentrationen).

In der Praxis hat sich die Auswertung mit Hilfe einer graphischen Eichkurve bewährt. An Hand von Eichlösungen mit konstantem inneren Standard, mit denen der ganze Analysengang durchgeführt wird, errechnet man einen Faktor $(f): f=\frac{F_{x}}{F_{S t}}$. Auf der Abszisse trägt man die eingesetzte Menge, auf der Ordinate den errechneten Faktor $f$ ab. In einem Chromatogramm mit unbekannten Mengen bestimmt man den Faktor $f$ und liest auf der Eichkurve ab. - Die Auswertung der Chromatogramme erfolgte durch Ausmessen als Höhe mal Breite in 15 und $85 \%$ der Höhe.

\section{Ergebnisse}

Abbildung 1 zeigt ein Testchromatogramm von 8 verschiedenen Steroiden als Silyläther.

Aus der Darstellung geht hervor, daß die einzelnen Steroide sehr gut voneinander trennbar sind. In Tabelle 1 sind die Retentionszeiten dieser 8 Steroide bei den oben beschriebenen Kolonnenbedingungen angegeben.

Tab. 1

Relative Retentionszeiten bezogen auf Cholestan

$\begin{array}{lr}\text { Cholestan } & =1,00 \text { (8 Min.) } \\ \text { Allo-Pregnandiol } & =0,77 \\ \text { Pregnandiol } & =0,88 \\ \text { Androsteron } & =0,96 \\ \text { Etiocholanolon } & =1,16 \\ \text { Dehydroepiandrosteron } & =1,34 \\ \text { Pregnanolon } & =1,57 \\ \text { Pregnantriol } & =1,88 \\ \text { Pregnantriolon } & =4,24\end{array}$




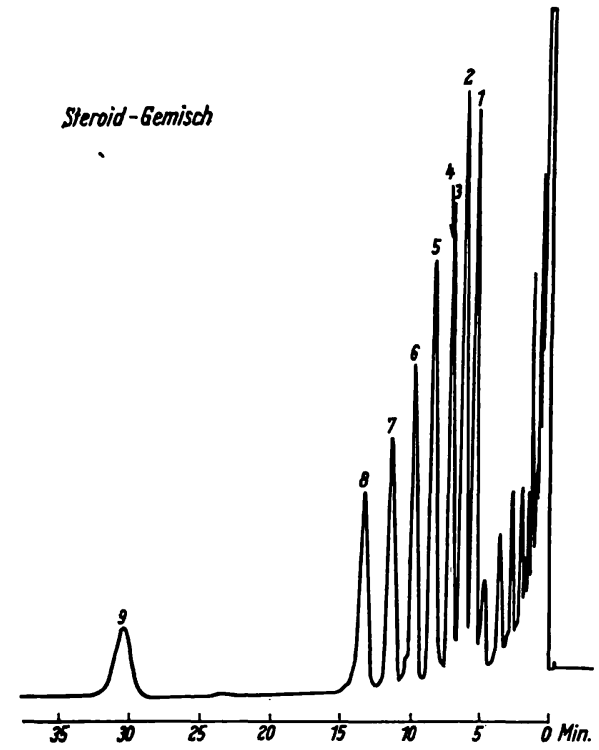

Abb. 1

Gaschromatogramm der Silyläther von Steroiden

$1=$ Allopregnandiol

$2=$ Pregnandiol

$3=$ Androsteron

$4=$ Cholestan

$5=$ Etiocholanolon

$6=$ Dehydroepiandrosteron

$7=$ Pregnanolon

$8=$ Pregnantriol

$9=$ Pregnantriolon

Trennbedingungen siehe Text; eingesetzt: $2 \mu l$
In Abbildung 2 ist eine Konzentrationsreihe von 100 bis $1000 \mu \mathrm{g}$ pro Probe Pregnandiol, Pregnantriol und Pregnantriolon dargestellt. Der alkoholischen Lösung der Testsubstanzen wurde wie unter $1 \mathrm{~b}$ beschrieben einerseits Urin und andererseits Wasser zugemischt und durch den gesamten Analysengang geführt. Die graphische Darstellung zeigt, daß die Ausbeute annähernd $100 \%$ beträgt und daß eine lineare Beziehung $z$ wischen Peakfläche und Konzentration besteht.

Abbildung 3 zeigt die Gaschromatogramme des gleichen Urins unter gleichen Bedingungen und mit gleicher Menge Ausgangsmaterial, links nach salzsaurer Hydrolyse und rechts nach Hydrolyse mit $\beta$-Glucuronidase.

Aus der Abbildung geht hervor, daß durch die salzsaure Hydrolyse Pregnantriol und Pregnantriolon weitgehend zerstört werden. Außer der Hydrolyse ist auch das verwendete Extraktionsmittel von großer Bedeutung. In Abbildung 4 sind die Gaschromatogramme mit verschiedenen Extraktionsmitteln bei gleicher Menge Ausgangsmaterial und unter gleichen Bedingungen dargestellt. Die Extraktion mit Toluol ist nicht quantitativ, besser eignet sich Methylenchlorid, die besten Resultate wurden jedoch mit Äther erzielt.

Um die Reproduzierbarkeit der Methode zu prüfen, wurden 5 Proben desselben Patientenurins analysiert. Die Ergebnisse sind in Tabelle 2 dargestellt.
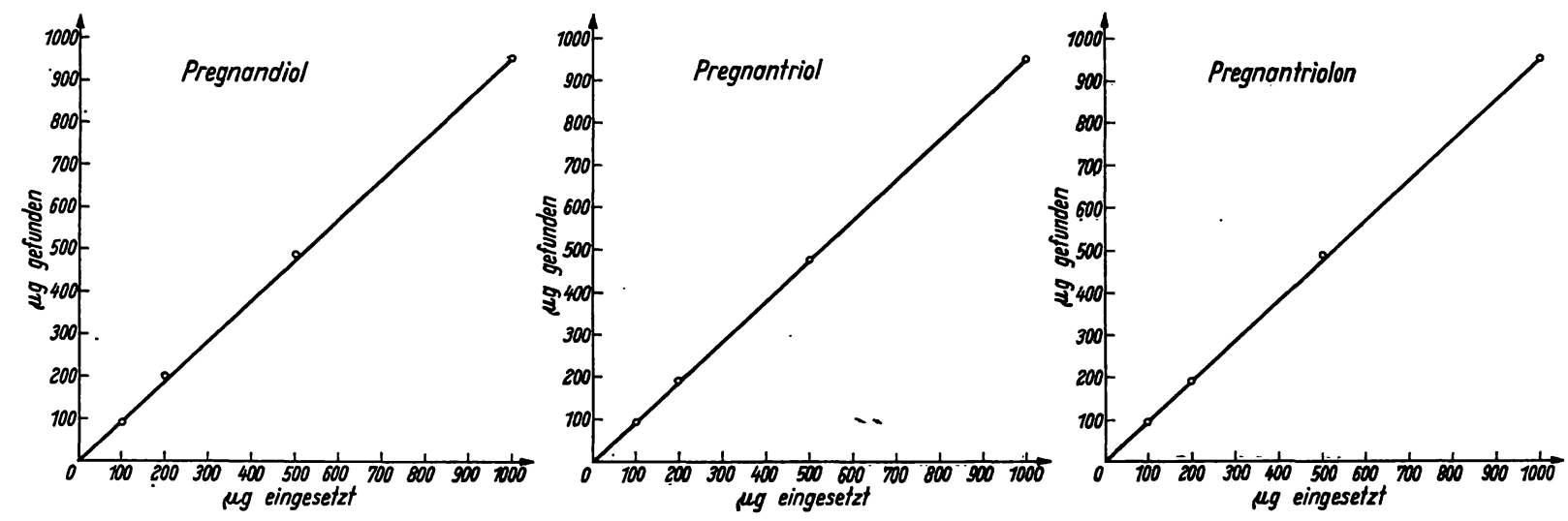

Abb. 2
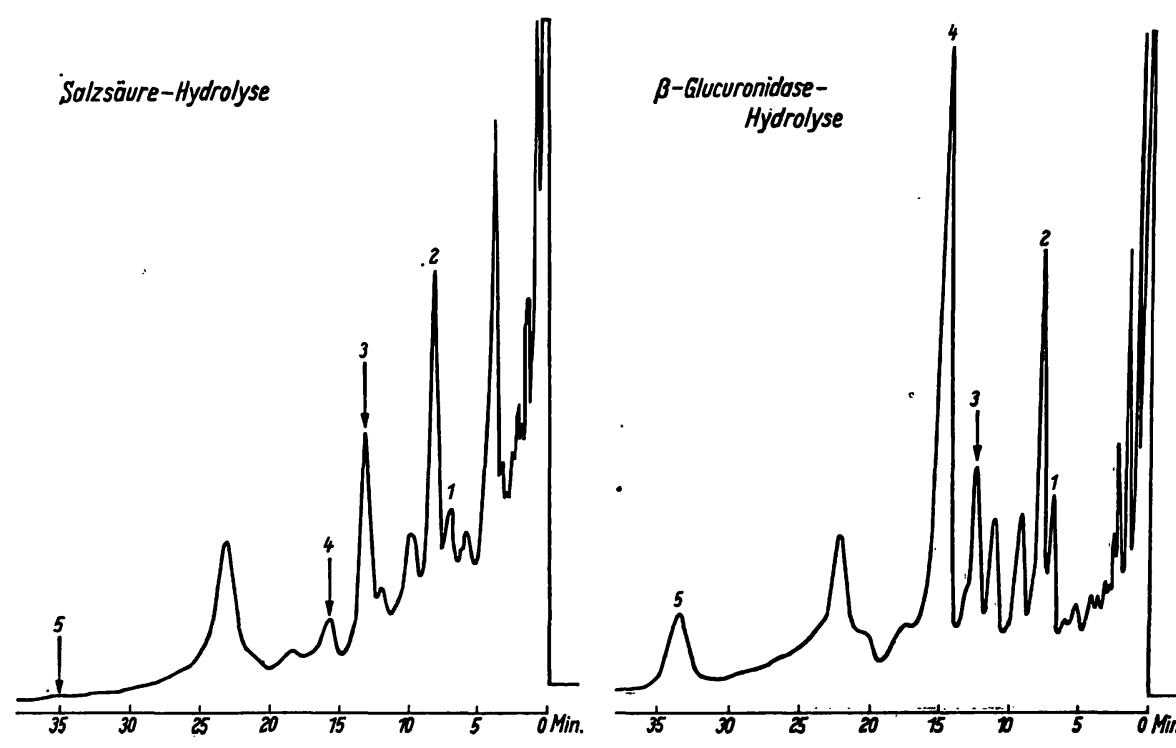

Abb. 3

Einfluß der Hydrolyse-Bedingungen auf die Gaschromatogramme von Steroiden

Links: salzsaure Hydrolyse rechts: enzymatische Hydrolyse

$1=$ Pregnandiol

$2=$ Androsteron

$3=$ Pregnanolon (Inn. Standard)

$4=$ Pregnantriol Trennbedingungen siehe Text; eingesetzt:

links: $1 \mu l$;

rechts: $0,7 \mu l$

$5=$ Pregnantriolon 

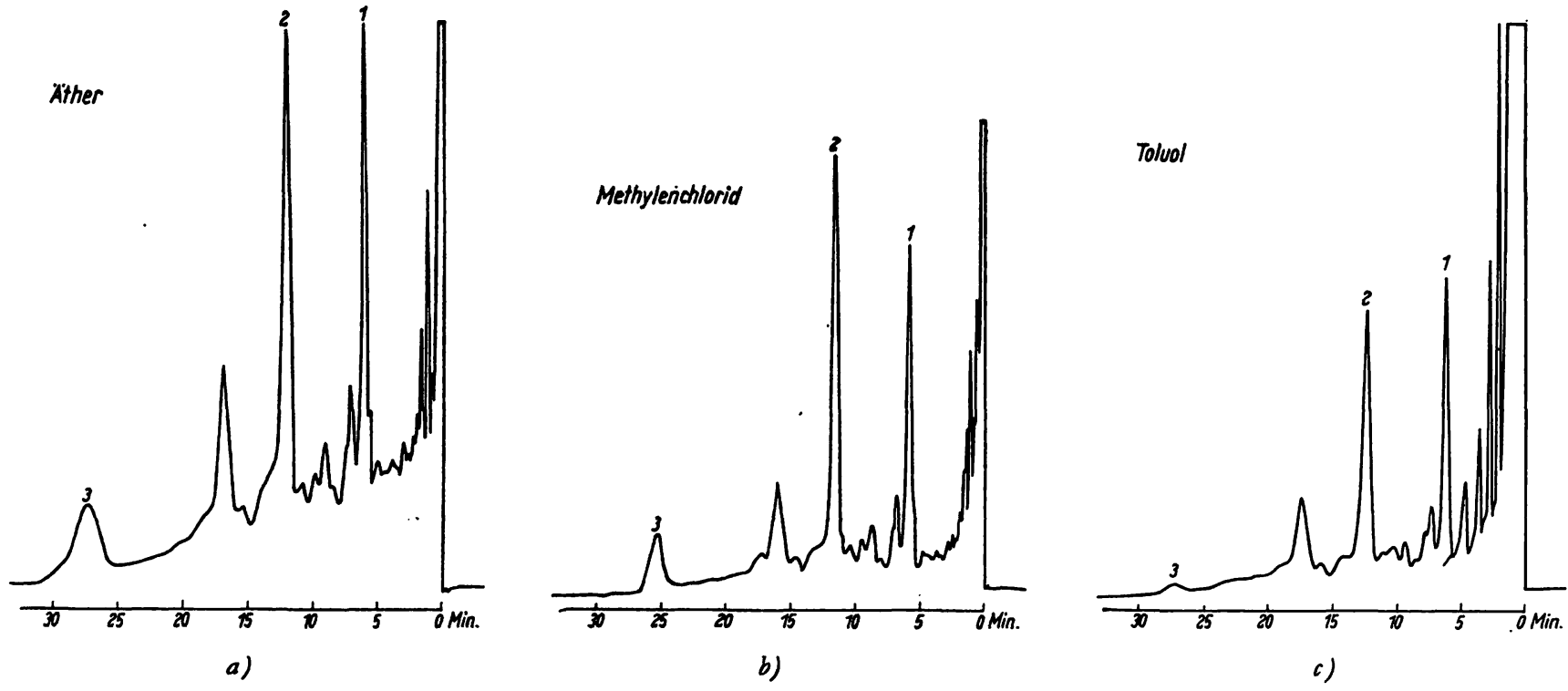

Abb. 4

Einfluß der Extraktionsmittel auf die Gaschromatogramme von Steroiden

$1=$ Androsteron

$2=$ Pregnantriol

$3=$ Pregnantriolon. Trennbedingungen siehe Text; eingesetzt: a) $0,5 \mu l$, b) $0,4 \mu l$, c) $0,2 \mu l$.

Tab. 2

Prüfung der Reproduzierbarkeit der Methode an einem Urin (adrenogenitales Syndrom) Werte in $\mu \mathrm{g} \%$

\begin{tabular}{cccc}
\hline & Pregnandiol & Pregnantriol & Pregnantriolon \\
\hline 1. & 180 & 2640 & 1150 \\
2. & 160 & 2560 & 940 \\
3. & 180 & 2640 & 940 \\
4. & 220 & 2840 & 1160 \\
5. & 200 & 2880 & 1000 \\
\hline Arith. Mittel: & $188 \pm 18$ & $2712 \pm 118$ & $1038 \pm 74$
\end{tabular}

In Tabelle 3 sind die Analysen-Ergebnisse verschiedener Patientenurine aufgeführt.

\section{Diskussion}

In der vorliegenden Arbeit wird eine gaschromatographische quantitative Methode beschrieben, die sich anstelle der bisher verwendeten konventionellen $\mathrm{Me}-$ thoden für die routinemäßige Bestimmung der Progesteron-Metaboliten eignet.

In der letzten Zeit haben sich verschiedene Autoren mit der Gaschromatographie von Steroiden in biologischem Material beschäftigt. So beschreiben FRANCE und Mitarbeiter die Bestimmung von Androsteron, Etiocholanolon und Dehydroepiandrosteron im Urin als Silyläther (14), Worrz und Mitarbeiter die Bestimmung von Pregnandiol im Urin mit Hilfe der Acetate (12), und in neuerer Zeit berichten HaMmoND und LeACH (15) in

Tab. 3

Gaschromatographisch bestimmte Gehalte in 24-Stdn.-Harnen von Patienten. Werte in $\mu \mathrm{g} \%$ bzw. in (mg/24-Stdn.-Harn)

\begin{tabular}{|c|c|c|c|c|c|}
\hline Name & Geschlecht & Alter i. J. & Pregnandiol & Pregnantriol & Pregnantriolon \\
\hline \multicolumn{6}{|c|}{ Unbebandeltes kongenitales adrenogenitales Syndrom } \\
\hline $\begin{array}{l}\text { M. K. } \\
\text { K. P. } \\
\text { H. J. } \\
\text { P. S. } \\
\text { S. M. } \\
\text { S. T. } \\
\text { S. H. }\end{array}$ & $\begin{array}{l}\text { o } \\
o+ \\
0 \\
0 \\
0 \\
+ \\
+ \\
0 \\
o\end{array}$ & $\begin{array}{l}16 \\
13 \\
6 \\
5 \\
1 \\
0,1 \\
0,1\end{array}$ & $\begin{aligned} 1920 & (16,32) \\
188 & (2,20) \\
400 & (1,60) \\
160 & (1,17) \\
50 & - \\
50 & - \\
- & -\end{aligned}$ & $\begin{aligned} 6800 & (57,80) \\
2712 & (32,50) \\
4500 & (18,00) \\
4000 & (29,20) \\
2000 & (2,40) \\
200 & (1,10) \\
80 & (0,19)\end{aligned}$ & $\begin{aligned} 2300 & (19,65) \\
1038 & (12,40) \\
800 & (3,20) \\
300 & (2,19) \\
700 & (0,84) \\
240 & (1,30) \\
60 & (0,14)\end{aligned}$ \\
\hline \multicolumn{6}{|c|}{ Bebandeltes kongenitales adrenogenitales Syndrom } \\
\hline $\begin{array}{l}\text { B. E. } \\
\text { B. E. } \\
\text { F. B. } \\
\text { M. I. }\end{array}$ & $\begin{array}{l}0 \\
0 \\
0 \\
0 \\
0 \\
+\end{array}$ & $\begin{array}{r}14 \\
11 \\
7 \\
6\end{array}$ & $\begin{array}{rr}-\overline{50} & - \\
160 & (1,05) \\
140 & (0,78)\end{array}$ & $\begin{array}{r}660(7,26) \\
400(4,60) \\
1340(8,78) \\
1680(9,41)\end{array}$ & $\begin{aligned} 280 & (3,08) \\
50 & - \\
1740 & (11,40) \\
500 & (2,80)\end{aligned}$ \\
\hline \multicolumn{6}{|c|}{ Nicbtbestätigter Verdacht auf adrenogenitales Syndrom } \\
\hline $\begin{array}{l}\text { H. L. } \\
\text { C. A. } \\
\text { F. R. }\end{array}$ & $\begin{array}{l}0 \\
+ \\
0 \\
0 \\
0\end{array}$ & $\begin{array}{c}12 \\
0,1 \\
0,1\end{array}$ & $\begin{array}{ll}- \\
-\end{array}$ & $\begin{array}{r}160(0,72) \\
60(0,30) \\
50-\end{array}$ & $\begin{array}{ll}\overline{5} & - \\
<50\end{array}$ \\
\hline
\end{tabular}


einer Kurzmitteilung über die Gaschromatographie von Progesteron-Metaboliten. - Die gaschromatographische Methode ist den konventionellen Methoden, wie z. B. Papier-, Dünnschicht- und Kolonnen-Chromatographie, in verschiedener Hinsicht überlegen. So ist eine quantitative Bestimmung im Nanogrammbereich möglich. Die Methode ist auch viel weniger zeitraubend und spezifischer als die konventionellen Trennungs- und Nachweismethoden (3-7).

Die Aufarbeitung des Urins - Hydrolyse und Extraktion - wurde nach den bekannten und vielgebrauchten Verfahren durchgeführt. Bei unserem Analysengang erübrigte sich eine weitere Reinigung mittels Kolonnenoder präparativer Dünnschichtchromatographie. Anschließende gaschromatographische Analysen eignen sich sehr gut, verschiedene Hydrolyse- und ExtraktionsVerfahren zu prüfen. So kann auf Grund der gezeigten Resultate die salzsaure Hydrolyse nicht mehr empfohlen werden, da sie die empfindlicheren Steroidmoleküle zerstört. Vor allem tritt beim Pregnantriol und Pregnantriolon Zersetzung ein; Pregnandiol hingegen übersteht sie ohne Verluste. Für die Progesteron-Metabolite ist deshalb die enz ymatische Hy'drolyse mit Glucuronidase die Methode der Wahl. Andere Konjugate als Glucuronide treten bei diesen Verbindungen nur in zu vernachlässigenden Konzentrationen auf.

Die Verwendung verschiedener Extraktionsmittel zeigte, daß unpolare Lösungsmittel, wie z. B. Toluol für die Extraktion ungeeignet sind und daß Äther die besten Resultate liefert.

Zur Entfernung der Oestrogene verwendeten wir $2 n$ Sodalösg., da mit Natronlauge Zersetzungen entstehen. Wichtig ist, daß die ätherische Phase anschließend vollkommen neutral gewaschen wird. Spuren von Alkali, die

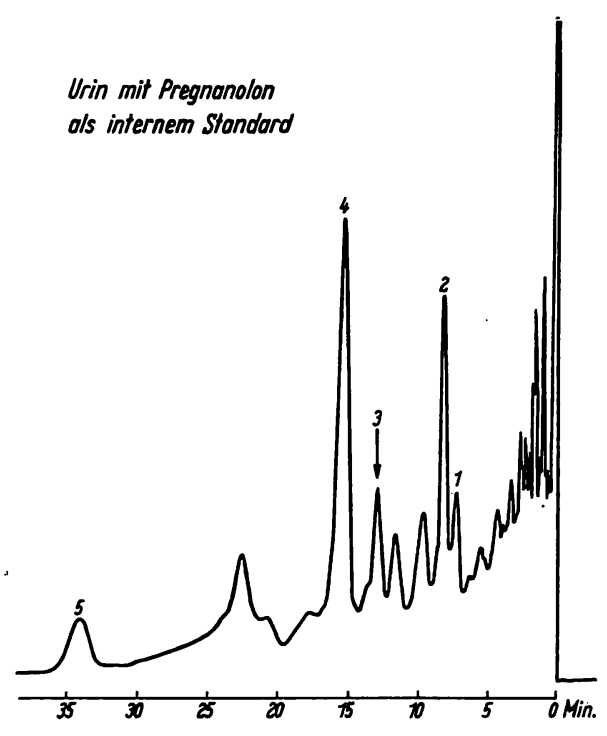

Abb. 5

Gaschromatogramm eines Urins mit Pregnanolon-Zusatz als inneren Standard. Trennbedingungen siehe Text; eingesetzt: $0,7 \mu l$

$1=$ Pregnandiol

$2=$ Androsteron

3 = Pregnanolon (Inn. Standard)
. im Analysengang mitgeführt werden, können bei der Injektion in den Gaschromatographen im Einspritzblock Zersetzung der Analysensubstanz hervorrufen.

Die Silyläther, deren Verwendung zuerst von HoRNING und Mitarbeitern (11) beschrieben wurde, scheinen uns die geeignetsten Derivate für die Gaschromatographie der Steroide zu sein. Man erzielt praktisch quantitative Ausbeuten und die Verbindungen sind sehr gut flüchtig. Auch tritt bei den verwendeten Temperaturen keine Zersetzung ein. Die Silyläther sind aber außerordentlich wasserempfindlich. Schon Spuren von Luftfeuchtigkeit können das Analysenergebnis in Frage stellen. Bei Beachtung aller Vorsichtskautelen erscheinen sie uns aber als die geeigneten Derivate. Von der Verwendung von Acetaten haben wir abgesehen, da unseres Erachtens das Risiko von $\beta$-Eliminierung bei den hohen Kolonnentemperaturen groß ist und somit unkontrollierbare Zersetzungsprodukte entstehen können.

Für die quantitative Bestimmung ist die Verwendung eines inneren Standards notwendig. $\mathrm{Da}$ aber die Urinchromatogramme eine sehr große und wechselnde Zahl von Peaks aufweisen, muß in diesem Fall anstelle eines substanzfremden, nicht in der Probe vorkommenden Stoffes, ein substanzeigener (evtl. im Urin vorkommender Stoff) Standard eingeführt werden. Für diesen Zweck eignet sich Pregnanolon oder auch Etiocholanolon gut. Praktisch muß man so vorgehen, daß von der gleichen Probe zwei Chromatogramme hergestellt werden, das eine mit, das andere ohne Zugabe von Pregnanolon. Da wir aber nur selten Pregnanolon feststellen konnten, erübrigt sich im allgemeinen die zweite Analyse. In Abbildung 5 ist das Gaschromatogramm eines Urins mit Pregnanolon als innerer Standard dargestellt.

Um ein „tailing“ zu vermeiden, wurde mit herabgesetzter Empfindlichkeit und mit $25 \mathrm{~m} l$ Urin gearbeitet. Die Empfindlichkeit kann aber bis weit unter $1 \mu \mathrm{g}$ pro Probe gesteigert werden.

So wurde die Methode durch Zumischen aufsteigender Steroidkonzentrationen zu Urin und Wasser getestet. Nach Durchführung des ganzen Arbeitsganges mit den Analysensubstanzen, einschließlich Hydrolyse, Extraktion und Silylierung wurden die erhaltenen Werte graphisch aufgetragen. Die Ausbeute erwies sich als sehr gut. Aus wiederholten Bestimmungen des gleichen Urins ergab sich eine hohe Zuverlässigkeit der Analyse. Die kleinen Abweichungen sind nicht durch die Gaschromatographie, sondern durch die nicht ganz reproduzierbare enzymatische Hydrolyse der Glucuronide verursacht.

Die Untersuchungen an Patienten aus unserer Klinik zeigen, daß die Methode für diagnostische Zwecke sehr gut geeignet ist. Erwartungsgemä $\beta$ erhielten wir bei $\mathrm{Pa}$ tienten mit adrenogenitalem Syndrom eine massive Erhöhung von Pregnantriol und Pregnantriolon im Falle eines 21-Hydroxylase-Defektes $(18,19)$.

Wir möchten Herrn Dr. R. NEHER von der Ciba AG, Basel für die Ubberlassung von Tesțsubstanzen unseren verbindlichsten Dank aussprechen. 


\title{
Literatur
}

1. Vesterganrd, P., Acta endocr., K'hvn. Supp. 64, 50 (1964). 2. Burstein, S. und S. Lieberman, J. biol. Chemistry 233, 331 (1958). - 3. De Watteville, H., R. Borth und M. Gsell, J. Clin. Endocr., Springfield 8, 962 (1948). - 4. BongrovanNI, A. M. und W. R. Eberlein, Analytic Chem. 30, 388 (1958). - 5. Martin, M. M., W. J. Reddy und G. W. Thorn, J. Clin. Endocr., Springfield 21, 923 (1961). - 6. Starka, L. und J. Malikova, J. Endocr. 22, 215 (1961). - 7. Oertel, G. W. und K. Groor, Clin. chim. Acta (Amsterdam) 11, 512 (1965). - 8. LipsKY, S. R. und R. A. LANDawne, Analytic Chem. 33, 818 (1961). - 9. Wotrz, H. H. und H. F. Martin, J. biol. Chemistry 236, 1312 (1961).- 10. Vandenreuvel, W. J. A., C. C. Sweeley und E. C. Horning, J. Amer. chem. Soc. 82, 3481 (1962). - 11. Horning, E. C., W. J. A. VAN-
Deniauvel und B. G. Creech, Methods of Biochem. Analysis, Vol. 2, Interscience, New York (1963). - 12. Wotrz, H. H., Biochim. biophysica Acta (Amsterdam) 69, 415 (1963). - 13. JANSEN, A. P., Clin. chim. Acta (Amsterdam) 8, 785 (1963). - 14. FRANCE, J. T., R. Rivera, N. L. McNiven und R. I. Dorfaran, Steroids 5 , 687 (1965). - 15. Hammond, K. B. und H. Leach, Clin. chim. Acta (Amsterdam) 11, 584 (1965). - 16. Klopper, A., E. A. MIchie und J. B. Brown, J. Endocr. 12, 209 (1955). - 17. Peterson, R. E., J. B. Wyngaarden, S. L. Guerra, B. B. Brodie und J. J. Bunim, J. Clin. Invest. 34, 1779 (1955). - 18. Bongiovanni, A.M., W. R. Eberlein und J. Cara, J. Clin. Endocr., Springfield 14, 409 (1954). - 19. Finkelstein, M. und J. Shoenderger: J. Clin. Endocr., Springfield 19, 608 (1959).

\section{Dr. H.-Ch. Curtius}

CH 8032 Zürich, Steinwiesstr. 75

\section{Bestimmung von Kreatin in Serum und Urin}

\author{
Von K. LAUBer \\ Aus dem Mediqinisch-Chemischen Institut der Universität Bern (Direktor: Prof. Dr. med. H. Aebi)
}

(Eingegangen am 20. September 1965)

\begin{abstract}
Eine cinfache Methode zur Bestimmung von Kreatin in Serum und Urin mit der Diacetylreaktion wird beschrieben. Das Serum wird mit Perchlorsäure enteiweißt. Enteiweißtes Serum bzw. Urin werden mit einem Farbreagenz bestehend aus Diacetyl und 1-Naphthol in Natronlauge zur Reaktion gebracht und photometriert. Die Messung der Extinktion nach zwei verschiedenen Zeiten erlaubt eine Korrektur des durch andere Guanidinderivate verursachten Fehlers. Die optimalen Reaktionsbedingungen werden diskutiert. Der Normalbereich im Serum wird ermittelt.

A simple method is described for the determination of creatine by the diacetyl reaction in serum and urine. The serum is deproteinised with perchloric acid. Deproteinised serum or urine is reacted with a colorimetric reagent consisting of diacetyl and 1-naphthol in sodium hydroxide solution and the colour is measured photometrically. By measuring the extinction at two different time intervals, a correction may be made for the interference by other guanidine derivatives. The optimal reaction conditions are discussed. The normal values for serum are reported.
\end{abstract}

Für die Ermittlung des Kreatingehaltes von biologischen Flüssigkeiten stehen heute im wesentlichen drei Analysentypen zur Verfügung: I. Photometrische Bestimmung als Kreatinin nach vorangehender Zyklisierung im sauren Milieu in der Wärme; II. Photometrische Bestimmung nach Überführung in roten Farbstoff mittels Diacetyl und $\alpha$-Naphthol (Barritt-Reaktion); III. Enzymatische Bestimmung im optischen Test nach WARBURG.

Im klinischen Labor sind Kreatinbestimmungen relativ selten. Es besteht daher dàs Bedürfnis nach einer $\mathrm{Me}$ thode, die auch bei nur sporadischem Gebrauch mit möglichst geringem Aufwand möglichst zuverlässige Resultate liefert. Die nach Prinzip I arbeitenden Methoden sind von vornherein wenig geeignet, weil sie für jede Probe zwei Analysen erfordern (Kreatininbestimmung vor und nach Zyklisierung des Kreatins) und bei Gegenwart großer Mengen von präformiertem Kreatinin ungenau sind. Es sind außerdem zahlreiche Bedenken gegen diesen Analysentyp erhoben worden, wie gegen die relative Ungenauigkeit der Pikratmethode an sich (1); Zerstörung von Kreatinin durch das Erhitzen (2); Bildung von unspezifischen Chromogenen (3); unvollständige Umwandlung des Kreatins in Kreatinin bei Gegenwart von viel präformiertem Kreatinin (Gleichgewichtsbildung) (4). Die auf Prinzip III basierenden Verfahren besitzen wohl eine nicht zu überbietende Spezifität und haben für wissenschaftliche Reihenuntersuchungen entschieden den Vorrang. Bei seltener Anwendung sind aber auch sie umständlich und teuer, wegen der beschränkten Haltbarkeit der vielen Hilfspräparate (drei Enzyme, Adenosintriphosphat, Nikotinamid-adenindinukleotid, Phospho-enolpyruvat). ANDERson und Mitarbeiter (5) haben eine auf der Barritt-Reaktion aufbauende Methode beschrieben, welche eine genaue und spezifische Erfassung des Kreatins in Serum und Urin ermöglicht. Die Verwendung von mehreren Ionenaustauschern in Serie macht das Verfahren zeitraubend und für die nicht besonders geschulte Arbeits$\mathrm{kraft}$ wenig geeignet. Auch ist der Serumbedarf $(3-6 \mathrm{ml}$ ) für heutige Begriffe zu hoch. Das Verfahren von ABELIN und RaAflaub $(1,6)$ ist wohl einfach, liefert aber $z u$ kleine Extinktionen und läßt die Störfaktoren im Serum unberücksichtigt. Im folgenden wird eine Methode beschrieben und diskutiert, welche mit einem Minimum an Aufwand eine für klinische Belange hinreichend genaue Kreatinbestimmung in Serum und Urin erlaubt.

\section{Methodik \\ Reagenzien}

1. Perchlorsäure $6 \mathrm{~g} / 100 \mathrm{~m} /(0,6 n): 5,2 \mathrm{~m} / 70$-proz. Säure mit Wasser ad $100 \mathrm{ml}$ (unbeschränkt haltbar).

2. Diacetyl: $0,5 \mathrm{~m} l / 100 \mathrm{~m} l$ Wasser (bei $4^{\circ}$ praktisch unbeschränkt haltbar). 